\title{
Risk of Hepatitis B Virus Reactivation in Rheumatoid Arthritis Patients Undergoing Tocilizumab-Containing Treatment
}

\author{
Meng Hsuan Kuo ${ }^{1} \cdot$ Chih-Wei Tseng ${ }^{2,3}$ (1) - Ming-Chi Lu ${ }^{2,4} \cdot$ Chien-Hsueh Tung ${ }^{2,4} \cdot$ Kuo-Chih Tseng $^{2,3}$. \\ Kuang-Yung Huang ${ }^{2,4} \cdot$ Chi-Hui Lee ${ }^{1} \cdot$ Ning-Sheng Lai ${ }^{2,4}$
}

Received: 6 July 2020 / Accepted: 17 November 2020 / Published online: 2 January 2021

(c) Springer Science+Business Media, LLC, part of Springer Nature 2021

\begin{abstract}
Background and Aim To investigate the risk of hepatitis B virus reactivation in patients undergoing long-term tocilizumab therapy for rheumatoid arthritis.

Method From January 2011 through August 2019, a total of 97 patients were enrolled in this retrospective study. Clinical data, comedications, and the occurrence of $\mathrm{HBV}$ reactivation were recorded.

Results Seven patients were HBsAg+ (7.2\%), 64 were $\mathrm{HBsAg}-/ \mathrm{HBcAb}+(65.9 \%)$, and 26 were $\mathrm{HBsAg}-/ \mathrm{HBcAb}-(26.8 \%)$. The median disease follow-up time was 9 years. TCZ was administered for a median of 29 months. Four patients $(4.1 \%)$ experienced HBV reactivation after tocilizumab therapy. Of the $7 \mathrm{HBsAg}+$ patients, 4 received antiviral prophylaxis and had no HBV reactivation; the remaining 3 patients did not receive antiviral prophylaxis, and all 3 (100\%) experienced HBV reactivation and hepatitis flare-up. Hyperbilirubinemia occurred in 2 of these 3 patients, with mild prothrombin time prolongation in one. After salvage entecavir treatment, all patients had a favorable outcome. Of the $64 \mathrm{HBs} \mathrm{Ag}-/ \mathrm{HBc} \mathrm{Ab}+$ patients, only one became positive for serum HBV DNA $\left(2.5 \times 10^{7} \mathrm{IU} / \mathrm{mL}\right)$ after 18 months of tocilizumab treatment $(1.6 \% ; 1 / 64)$. This patient was immediately treated with entecavir, which prevented hepatitis flare-up.

Conclusions Tocilizumab is widely used in treating rheumatoid arthritis and has the potential to reduce the mortality rate among severe COVID-19 patients. However, HBV reactivation needs to be considered. HBsAg+ patients have a high risk of $\mathrm{HBV}$ reactivation, which could be prevented by antiviral prophylaxis. Although the risk of reactivation is low in $\mathrm{HBsAg}-/$ $\mathrm{HBcAb}+$ patients, strict monitoring is necessary.
\end{abstract}

Keywords HBV reactivation $\cdot$ Hepatitis flare-up $\cdot$ Rheumatoid arthritis $\cdot$ Tocilizumab

Electronic supplementary material The online version of this article (https://doi.org/10.1007/s10620-020-06725-1) contains supplementary material, which is available to authorized users.

Chih-Wei Tseng

cwtseng2@gmail.com

1 Department of Pharmacy, Dalin Tzu Chi Hospital, Buddhist Tzu Chi Medical Foundation, Chia-Yi, Taiwan

2 School of Medicine, Tzuchi University, Hualien, Taiwan

3 Division of Gastroenterology, Department of Internal Medicine, Dalin Tzu Chi Hospital, Buddhist Tzu Chi Medical Foundation, No. 2, Minsheng Rd., Dalin Township, Chia-Yi County 62247, Taiwan

4 Division of Rheumatology, Department of Internal Medicine, Dalin Tzu Chi Hospital, Buddhist Tzu Chi Medical Foundation, Chia-Yi, Taiwan

\begin{tabular}{ll}
\multicolumn{2}{l}{ Abbreviations } \\
ALT & Alanine aminotransferase \\
AST & Aspartate aminotransferase \\
HBV & Hepatitis B virus \\
HBsAg & HBV surface antigen \\
HBcAb & HBV core antibody \\
HBsAb & HBV surface antibody \\
HCV & Hepatitis C virus \\
IL & Interleukin \\
RA & Rheumatoid arthritis \\
sDMARDs & Synthetic disease-modifying antirheumatic \\
& drugs \\
bDMARDs & Biological disease-modifying antirheumatic \\
& drugs \\
TCZ & Tocilizumab \\
T.bil & Total bilirubin \\
TNF & Tumor necrosis factor
\end{tabular}




\section{Introduction}

The risk of hepatitis B virus (HBV) reactivation during immunosuppressive therapy in patients with chronic or occult HBV infection is increasingly recognized in different disciplines of medicine, including rheumatology $[1,2]$. The consequences of HBV reactivation during immunosuppressive therapy range from an asymptomatic increase in serum HBV DNA levels to fatal hepatic failure [3]. In rheumatoid arthritis (RA), HBV can be reactivated by changes in the disease course and by drug use [4-7]. Inflammatory arthritis patients receiving biological disease-modifying antirheumatic drugs (bDMARDs) are thought to have a moderate risk (1-10\%) of HBV reactivation [7]. A previous study reported that without antiviral prophylaxis, HBV reactivation occurs in $62.5 \%$ of $\mathrm{HBV}$ carriers and $25 \%$ of patients with occult HBV infection undergoing treatment with tumor necrosis factor (TNF)alpha blockers [8].

Tocilizumab (TCZ), a humanized monoclonal antibody that selectively neutralizes both the soluble and membrane-bound forms of interleukin (IL)-6 receptor, is a developed biological agent that effectively alleviates RA disease symptoms. Recently, tocilizumab has been applied in patients with severe COVID-19 to reduce the cytokine storm and has the potential to reduce the mortality rate $[9,10]$. However, the risk of HBV reactivation needs to be considered. Several studies have revealed that IL-6 could suppress HBV replication and mediate HBV entry into hepatocytes $[11,12]$. Nonparenchymal liver cells, most likely Kupffer cells, recognize HBV patterns and induce the IL-6-mediated block of HBV replication at the transcriptional level [13]. IL-6 inhibits HBV replication through a moderate reduction in viral transcripts, similar to IL-4 and transforming growth factor $-\beta 1$, and a more dramatic reduction in viral genome-containing nucleocapsids, similar to interferon [14]. In addition, the accumulation of HBV covalently closed circular DNA could be blocked by IL-6 [14]. Therefore, biological agents that therapeutically decrease IL-6 levels, such as tocilizumab, may present a risk of HBV reactivation.

Current treatment guidelines suggest that antiviral prophylaxis should be initiated before immunosuppressive or cytotoxic therapy in HBV surface antigen-positive (HBsAg+) patients $[7,15,16]$. However, determining the risk of TCZ-induced HBV reactivation is difficult due to a lack of prospective controlled studies. Studies investigating the risk of HBV reactivation in $\mathrm{HBsAg}+$ patients receiving TCZ have demonstrated controversial results [17-20]. The reactivation rate ranged from 0 to $60 \%$ in HBsAg+ patients who underwent TCZ without antiviral prophylaxis [17-19], and in one case, the patient even required liver transplantation due to hepatic failure [21]. For $\mathrm{HBsAg}-/ \mathrm{HBV}$ core antibody-positive $(\mathrm{HBcAb}+)$ patients, the HBV reactivation rate is also inconsistent [19, 22-27], and HBV reactivation always presents with virus reappearance and fluctuation [28-31]. These controversial results have increased the interest in studying the $\mathrm{HBVr}$ risk of TCZ.

The aim of this retrospective, real-world study was to determine the risk of HBV reactivation with long-term TCZ therapy for RA patients in our hospital.

\section{Methods}

\section{Patients}

We retrospectively reviewed the medical records of RA patients who had received TCZ therapy between January 2011 and August 2019 at Dalin Tzu Chi Hospital. The inclusion criteria were as follows: (1) fulfilled the RA classification criteria [32, 33]; (2) available $\mathrm{HBsAg}$ and $\mathrm{HBcAb}$ status at diagnosis; and (3) treated with TCZ for at least 3 months. Patients were excluded if they were $<20$ years of age or lacked the required data. In accordance with international guidelines, TCZ was administered at the standard intravenous dose of $4-8 \mathrm{mg} / \mathrm{kg}$ every 4 weeks or subcutaneous dosage of $162 \mathrm{mg}$ every $1-2$ weeks [34].

\section{Follow-Up of the Study Population}

Medical records were reviewed retrospectively. Baseline characteristics included serum markers of HBV [HBsAg, $\mathrm{HBcAb}$, hepatitis B surface antibody (HBsAb), and HBV DNA], anti-hepatitis $\mathrm{C}$ virus antibody (anti-HCV), liver biochemical parameters [serum aspartate aminotransferase (AST); alanine aminotransferase (ALT)], comorbidities, comedications, and the occurrence of HBV reactivation. Patients were monitored for ALT/AST levels every 3 months, and HBsAg and HBV DNA tests were performed whenever clinically indicated. Detailed medical records were collected, including immunological profiles, TCZ course, previous and concomitant DMARD therapy, and corticosteroid therapy.

\section{Assessment of HBV Reactivation and Hepatitis Flare-Up}

The primary endpoint of this study was HBV reactivation. For HBsAg+ patients, HBV reactivation was defined as (1) an increase in HBV DNA $>2 \log _{10}$ over that of baseline,(2) HBV DNA $>3 \log _{10}$ in a patient with previously undetectable level, or (3) an absolute level of HBV DNA $>4 \log _{10}$ if baseline level was unavailable [15]. A change in the HBV 
DNA titer from negative to positive or HBsAg seroreversion (HBsAg reappearance) was defined in $\mathrm{HBsAg}-/ \mathrm{HBcAb}+$ [15]. Hepatitis flare-up was defined as an ALT level elevated at least 3 times that of baseline and $>100 \mathrm{U} / \mathrm{L}$ [15].

\section{Statistical Analysis}

The data were analyzed using SPSS 19.0 for Windows (SPSS, Inc., Chicago, IL, USA). Categorical variables are presented as counts and percentages, and continuous variables are presented as the median value and range.

\section{Results}

\section{General Characteristics of the Study Subjects}

The enrolled patient distribution is illustrated in Fig. 1. Of the initial 134 RA patients receiving TCZ, 97 remained after the exclusion of patients with missing data regarding the HBsAg or HBcAb status $(n=25)$ or those who received TCZ for less than 3 months $(n=12)$. Of the included 97 patients, 7 were $\mathrm{HBsAg}+(7 / 97,7.2 \%)$, and 90 were HBsAg- (90/97, 92.8\%). Of the HBsAg- patients, 64 were $\mathrm{HBsAg}-/ \mathrm{HBcAb}+$, and 26 were $\mathrm{HBsAg}-/ \mathrm{HBcAb}-$. Four patients (4/97) experienced HBV reactivation during TCZ treatment. The HBV reactivation rate was 5.6\% (4/71) in the patients with a chronic or resolved HBV infection.
The clinical, serological, and virologic characteristics and therapeutic regimens of the patient cohort are shown in Table 1. The median age was 64 years (range, 38-87), and $75(77 \%)$ were female. The median disease follow-up time was 9 years (range, 1-18 years). TCZ was administered for a median of 29 months (range, 3-91) in combination with methotrexate (71 patients, $73 \%$ ) or a low dose of glucocorticoids (90 patients, 94\%). Seventy-one (73\%) patients had a history of other bDMARD treatments. Most patients had previously received adalimumab (45 patients; $46 \%$ ) or rituximab (25 patients; $26 \%$ ).

\section{Clinical Features of HBsAg+ Patients with HBV Reactivation}

The general characteristics of the $\mathrm{HBsAg}+$ patients are shown in Table 1 . Four patients $(57.1 \%)$ received antiviral prophylaxis, and none experienced $\mathrm{HBV}$ reactivation or hepatitis flare-up among the $4 \mathrm{HBsAg}+$ patients. In contrast, HBV reactivation and hepatitis flare-up were noted in all 3 patients without antiviral prophylaxis (Fig. 1). Clinical data for the patients with HBV reactivation are shown in Table 2. All were female (median age, 77 years; range, 56-78 years), and the median time to reactivation from the initiation of TCZ treatment was 6 months (range, 5-8 months). Hyperbilirubinemia was noted in 2 of the 3 patients, and a mildly prolonged prothrombin time was observed in one patient. No acute liver decompensation (i.e., ascites, hepatic encephalopathy, hepatorenal
Fig. 1 Flow diagram of study cohort characteristics. The flowchart shows the hepatitis B virus (HBV) infection serostatus distribution at baseline and the occurrence of $\mathrm{HBV}$ reactivation in rheumatoid arthritis (RA) patients treated with tocilizumab. Abbreviations: HBsAg, $\mathrm{HBV}$ surface antigen; $\mathrm{HBcAb}$, HBV core antibody

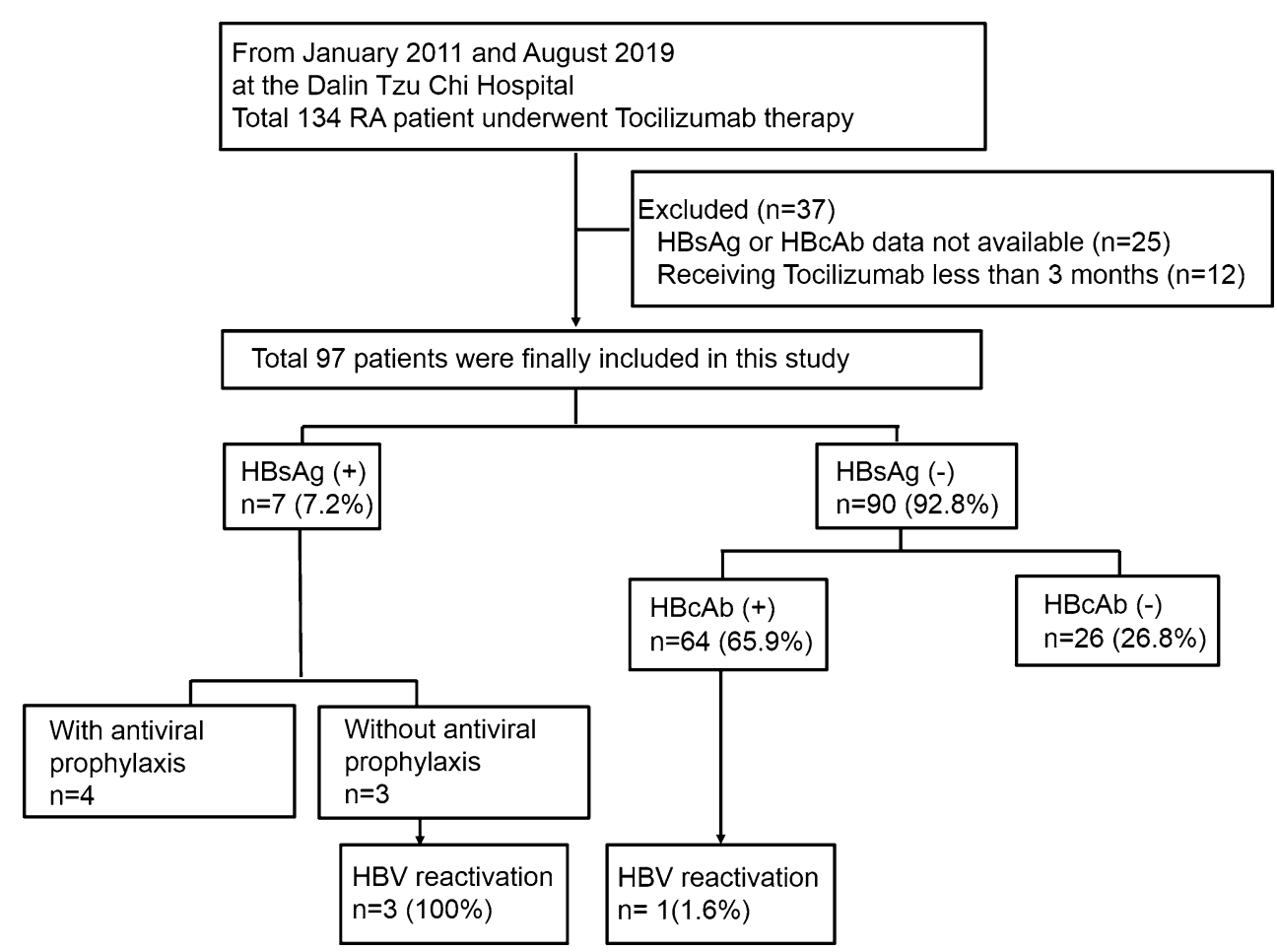


Table 1 Baseline patient characteristics

\begin{tabular}{|c|c|c|c|}
\hline & $\begin{array}{l}\text { All } \\
(N=97)\end{array}$ & $\begin{array}{l}\text { HBsAg+ } \\
(N=7)\end{array}$ & $\begin{array}{l}\mathrm{HBsAg}-/ \mathrm{HBcAb}+ \\
(\mathrm{N}=64)\end{array}$ \\
\hline Age $\left(\right.$ years) ${ }^{\mathrm{a}}$ & $64(38-87)$ & $65(56-78)$ & $67(38-87)$ \\
\hline Sex, female $n(\%)$ & $75(77 \%)$ & $5(71 \%)$ & $49(77 \%)$ \\
\hline Follow-up time (years) ${ }^{\mathrm{a}}$ & $9(1-18)$ & $9(2-14)$ & $9(1-18)$ \\
\hline Duration of TCZ therapy (months) ${ }^{a}$ & $29(3-91)$ & $16(4-66)$ & $26(3-84)$ \\
\hline Anti-HCV (+), $n(\%)$ & $14(14 \%)$ & $1(14 \%)$ & $11(17 \%)$ \\
\hline RF (IU/ml) & $505(10-6710)$ & $131(10.4-430)$ & $529(10-6710)$ \\
\hline Anti-CCP (EliA U/ml) & $74(0.3-448)$ & $98(0.3-340)$ & $72(0.3-448)$ \\
\hline $\mathrm{IgG}(\mathrm{mg} / \mathrm{dL})$ & $1578(664-2640)$ & $1754(1210-2240)$ & $1561(664-2640)$ \\
\hline \multicolumn{4}{|c|}{ Antirheumatic therapies before TCZ use, $n(\%)$} \\
\hline \multicolumn{4}{|l|}{ sDMARDs } \\
\hline Methotrexate & $91(94 \%)$ & $7(100 \%)$ & $62(97 \%)$ \\
\hline Azathioprine & $3(3 \%)$ & $0(0 \%)$ & $3(5 \%)$ \\
\hline Cyclosporine & $15(15 \%)$ & $3(43 \%)$ & $9(14 \%)$ \\
\hline Leflunomide & $45(46 \%)$ & $3(43 \%)$ & $26(41 \%)$ \\
\hline Sulfasalazine & $85(88 \%)$ & $6(86 \%)$ & $57(89 \%)$ \\
\hline Glucocorticoid (oral) $^{\mathrm{b}}$ & $96(99 \%)$ & $7(100 \%)$ & $63(98 \%)$ \\
\hline \multicolumn{4}{|l|}{ bDMARDs } \\
\hline Abatacept & $10(10 \%)$ & $1(14 \%)$ & $8(17 \%)$ \\
\hline Adalimumab & $45(46 \%)$ & $3(43 \%)$ & $31(48 \%)$ \\
\hline Etanercept & $22(23 \%)$ & $2(29 \%)$ & $11(17 \%)$ \\
\hline Golimumab & $13(13 \%)$ & $1(14 \%)$ & $8(13 \%)$ \\
\hline Rituximab & $25(26 \%)$ & $3(43 \%)$ & $12(19 \%)$ \\
\hline bDMARD naïve & $26(27 \%)$ & $0(0 \%)$ & $19(30 \%)$ \\
\hline \multicolumn{4}{|l|}{ Concomitant, $n(\%)$} \\
\hline Methotrexate & $71(73 \%)$ & $4(57 \%)$ & $47(73 \%)$ \\
\hline Glucocorticoid (oral) $^{\mathrm{b}}$ & $96(99 \%)$ & $7(100 \%)$ & $64(100 \%)$ \\
\hline Equivalent dose $(\mathrm{mg})^{\mathrm{c}}$ & $5(2-10)$ & $5(2.5-7.5)$ & $5(2-10)$ \\
\hline Low dose & $90(94 \%)$ & $7(100 \%)$ & $58(91 \%)$ \\
\hline Moderate dose & $6(6 \%)$ & $0(0 \%)$ & $6(9 \%)$ \\
\hline Azathioprine & $1(1 \%)$ & $0(0 \%)$ & $1(2 \%)$ \\
\hline Cyclosporine & $4(4 \%)$ & $1(14 \%)$ & $3(5 \%)$ \\
\hline Leflunomide & $21(22 \%)$ & $0(0 \%)$ & $13(20 \%)$ \\
\hline Sulfasalazine & $45(47 \%)$ & $3(43 \%)$ & $28(42 \%)$ \\
\hline
\end{tabular}

${ }^{\mathrm{a}}$ Data are presented as the median (range)

${ }^{\mathrm{b}}$ Glucocorticoids (oral): cortisone, prednisolone, methylprednisolone, dexamethasone

${ }^{\mathrm{c}}$ Prednisolone equivalent dose (mg/day): high dose, $>20 \mathrm{mg} /$ day $\geq 4$ weeks; moderate dose, $10-20 \mathrm{mg} / \mathrm{day} \geq 4$ weeks; low dose, $<10 \mathrm{mg} /$ day $\geq 4$ weeks

$\mathrm{HCV}$, hepatitis C virus; RF, rheumatoid factor; Anti-CCP, anti-cyclic citrullinated peptide antibody; IgG, Immunoglobulin G,HBsAg, HBV surface antigen; HBcAb, HBV core antibody; TCZ, tocilizumab; bDMARDs, biological disease-modifying antirheumatic drugs; sDMARDs, synthetic disease-modifying antirheumatic drugs

syndrome, or variceal bleeding) was reported. All 3 of these patients received the antiviral agent entecavir, which led to sustained viral suppression and smooth recovery with no complications. The time course of HBV reactivation is described below and shown in Fig. 2a-c and Table 2.

\section{Clinical Features of $\mathrm{HBsAg}-/ \mathrm{HBCAb}+$ Patients with HBV Reactivation}

The general characteristics of the $\mathrm{HBsAg}-/ \mathrm{HBcAb}+$ patients are shown in Table 1. With TCZ administration, one $\mathrm{HBsAg}-/ \mathrm{HBcAb}+$ patient $(1 / 64 ; 1.6 \%)$ experienced HBV reactivation (Fig. 1; Table 2). In this case, after 18 months of 
Table 2 Clinical features of RA patients who developed HBV reactivation during tocilizumab therapy

\begin{tabular}{|c|c|c|c|c|}
\hline \multirow[t]{2}{*}{ Data source } & \multicolumn{3}{|l|}{$\mathrm{HBsAg}+$} & \multirow{2}{*}{$\begin{array}{l}\mathrm{HBsAg}-/ \mathrm{HBcAb}+ \\
\text { Case } 4\end{array}$} \\
\hline & Case 1 & Case 2 & Case 3 & \\
\hline Age/sex & $56 / \mathrm{F}$ & $77 / \mathrm{F}$ & $78 / \mathrm{F}$ & $67 / \mathrm{F}$ \\
\hline RA disease duration (year) & 11 & 14 & 11 & 15 \\
\hline Duration of TCZ therapy (months) & 5 & 6 & 8 & 18 \\
\hline HBsAg seroreversion & - & - & - & + \\
\hline $\mathrm{HBsAb}$ & $\mathrm{N}$ & $\mathrm{N}$ & $\mathrm{N}$ & $\mathrm{N}$ \\
\hline Anti-HCV & NA & NA & $\mathrm{N}$ & $\mathrm{N}$ \\
\hline HBV DNA (peak, IU/mL) & $3.7 \times 10^{7}$ & $1.6 \times 10^{7}$ & $1.7 \times 10^{8}$ & $2.5 \times 10^{7}$ \\
\hline ALT (initial/peak, U/L) & $155 / 155$ & $698 / 946$ & $106 / 355$ & $98 / 107$ \\
\hline T.bil (initial/peak, mg/dL) & $0.6 / 1.3$ & $2.2 / 24.8$ & $1.1 / 4.3$ & $0.5 / 0.5$ \\
\hline PT prolongation & $\mathrm{N}$ & $\mathrm{N}$ & $\mathrm{Y}$ & $\mathrm{N}$ \\
\hline Ascites & $\mathrm{N}$ & $\mathrm{N}$ & $\mathrm{N}$ & $\mathrm{N}$ \\
\hline Hepatic encephalopathy & $\mathrm{N}$ & $\mathrm{N}$ & $\mathrm{N}$ & $\mathrm{N}$ \\
\hline Hepatitis flare-up & $\mathrm{Y}$ & $\mathrm{Y}$ & $\mathrm{Y}$ & $\mathrm{N}$ \\
\hline Treatment for HBV reactivation & ETV $0.5 \mathrm{mg}$ & ETV $0.5 \mathrm{mg}$ & ETV $0.5 \mathrm{mg}$ & ETV $0.5 \mathrm{mg}$ \\
\hline Outcome & Alive \& well & Alive \& well & Alive \& well & Alive \& well \\
\hline \multicolumn{5}{|l|}{ Antirheumatic therapies before TCZ } \\
\hline bDMARDs (months) & ADA (14) & ETN (5)/rituximab (20) & ETN (46)/rituximab (13) & $\begin{array}{l}\text { ETN (35)/ADA } \\
(25) / \text { rituximab } \\
(25) /\end{array}$ \\
\hline sDMARDs & MTX/Pd/SSZ/CSA & MTX/Pd/SSZ/LEF/CSA & MTX/Pd/SSZ/LEF & MTX/Pd/SSZ/LEF \\
\hline \multicolumn{5}{|l|}{ Concomitant immunosuppressants } \\
\hline MTX (mg/week) & 0 & 7.5 & 7.5 & 7.5 \\
\hline Prednisolone equivalent dose (mg/day) & 5 & 7.5 & 7.5 & 7.5 \\
\hline SDMARDs & $\mathrm{N}$ & SSZ & SSZ & SSZ \\
\hline
\end{tabular}

ETV, entecavir; IFX, infliximab; TAC, tacrolimus; RA, rheumatoid arthritis; HBV, hepatitis B virus; HCV, hepatitis C virus; F, female; TCZ, tocilizumab; HBsAg, HBV surface antigen; HBc Ab, HBV core antibody; ALT, alanine aminotransferase; IU, international units; T.bil, total bilirubin; PT, prothrombin time; sDMARDs, synthetic disease-modifying antirheumatic drugs; Pd, prednisolone; MTX, methotrexate; LEF, leflunomide; SSZ, sulfasalazine; CSA, cyclosporine, bDMARDs, biological disease-modifying antirheumatic drugs; ADA, adalimumab; ETN, etanercept; NA, not applicable; N, did not happen; Y, happened

TCZ treatment, HBsAg seroreversion with serum HBV DNA appearance $\left(2.5 \times 10^{7} \mathrm{IU} / \mathrm{mL}\right)$ was observed. Her serum ALT level remained stable without evidence of hepatitis flareup. Entecavir (0.5 mg/day) was initiated, and the HBV viral load was undetectable 22 months later. TCZ treatment was continued. The time course of $\mathrm{HBV}$ reactivation is described below and shown in Fig. 2 d.

\section{Discussion}

Our results show that RA patients receiving TCZ are at risk of $\mathrm{HBV}$ reactivation. The risk was very high for $\mathrm{HBsAg}+$ patients who were not administered an antiviral prophylactic agent $(3 / 3 ; 100 \%)$. This risk was eliminated by antiviral prophylaxis. HBV reactivation in $\mathrm{HBs} \mathrm{Ag}+$ patients often occurred within the first year of TCZ treatment (median administration time, 6 months; range, 5-8 months) and was associated with hepatitis flare-up. We also observed one case of $\mathrm{HBV}$ reactivation among $\mathrm{HBsAg}-/ \mathrm{HBc} \mathrm{Ab}+$ patients $(1 / 64 ; 1.6 \%)$.

Patients treated with TCZ are at risk of serious infections, including tuberculosis and other opportunistic bacterial, invasive fungal, and viral infections. The European Society of Clinical Microbiology and Infectious Diseases suggests that TCZ use puts patients at a modest risk of overall infection [16]. Because patients with HBV infection were excluded from pivotal TCZ trials [35, 36], the risk of HBV reactivation was not well reported.

Few studies with limited case numbers have investigated the risk of $\mathrm{HBV}$ reactivation among RA patients receiving TCZ treatment, especially in HBsAg+ patients without prophylactics (Supplement Table 1) [17-20, 22-31]. There have only been three studies, including 8 patients, on the HBV reactivation risk in $\mathrm{HBs} \mathrm{Ag}+$ patients, with a reported reactivation rate ranging from 0 to $60 \%$ [17-19]. The study from Taiwan that investigated HBV reactivation in RA patients undergoing biological treatment included two HBsAg+ 
Fig. 2 Time course of serum alanine aminotransferase and total bilirubin concentrations in patients experiencing HBV reactivation. Abbreviations:

ALT, alanine aminotransferase; T.bil, total bilirubin; HBV, hepatitis B virus; HBsAg, HBV surface antigen; $\mathrm{HBcAb}, \mathrm{HBV}$ core antibody; TCZ, tocilizumab; ETV, entecavir
(A)

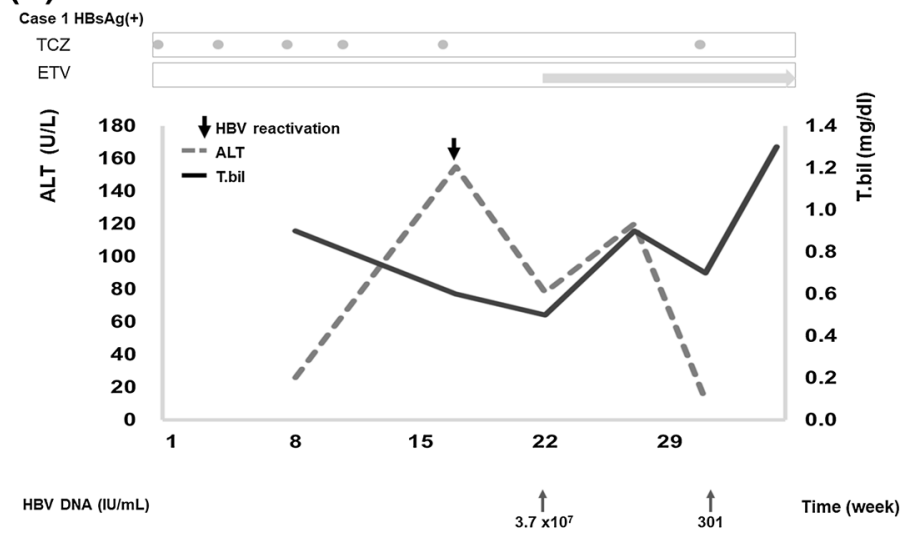

(B)

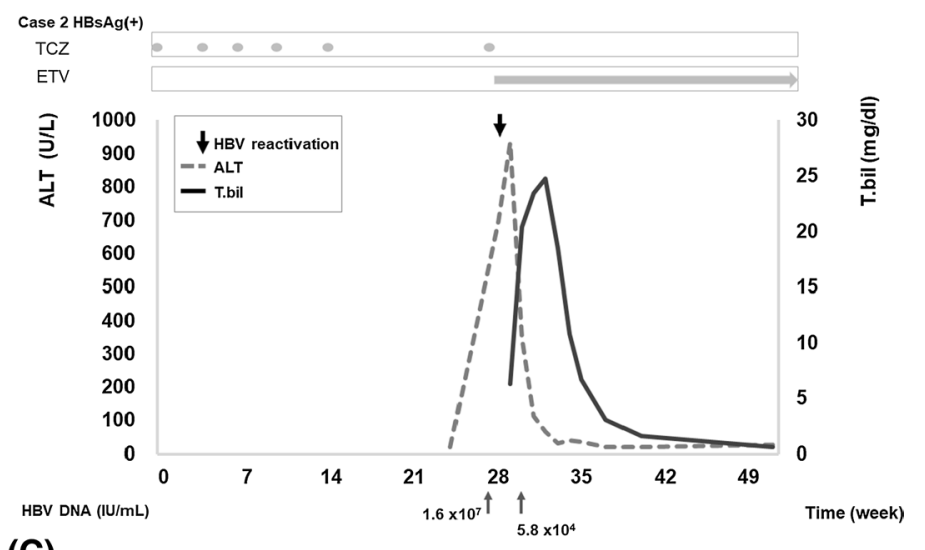

(C)

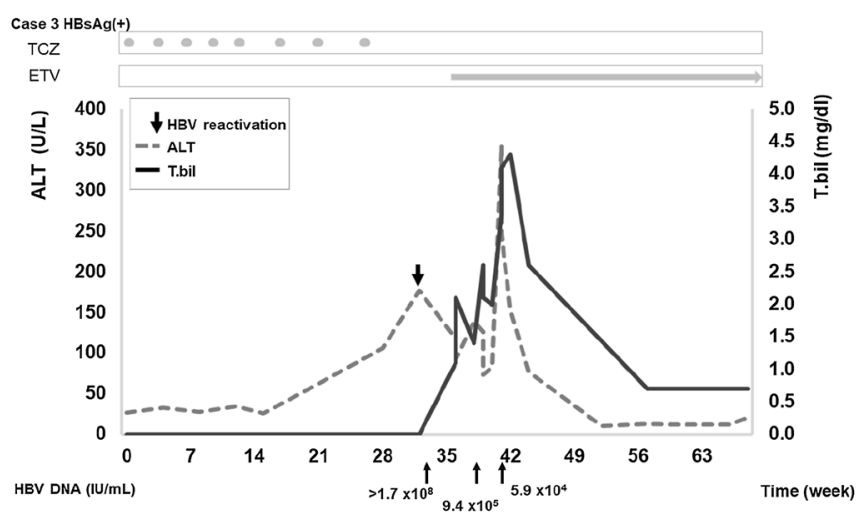

(D)

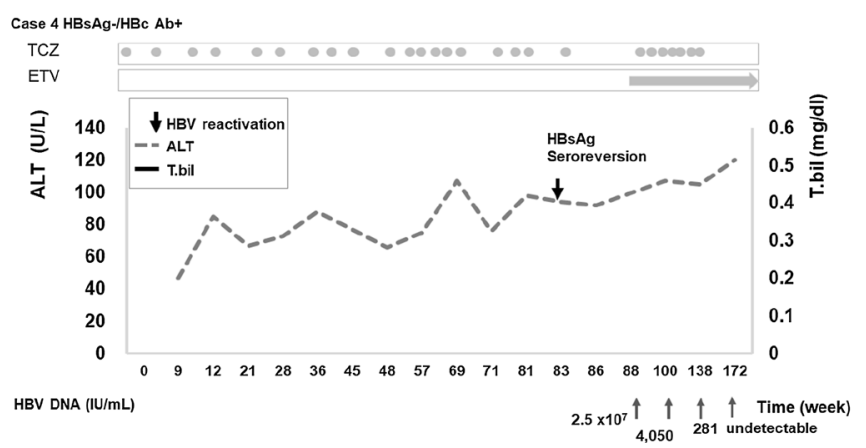


patients receiving TCZ, and both were free of reactivation [17]. Another study from Japan included only one HBsAg+ patient receiving TCZ, and no HBV reactivation was found [18]. A prospective study including $5 \mathrm{HBsAg}+\mathrm{RA}$ patients receiving TCZ reported an HBV reactivation rate of $60 \%$ (3/5) [19]. In the current cohort, the highest HBV reactivation rate $(100 \%)$ was noted. HBV reactivation was determined by the HBV serologic status [7, 37, 38], host immune status, treatment duration, glucocorticoid comedication [17], and history of bDMARD use [5, 39]. In the current study, all HBsAg+ patients underwent comedication with glucocorticoids and had a history of bDMARD use. These factors may explain the higher risk of HBV reactivation in our study. Without a suitable comparison population, the relationship of steroid and bDMARD treatment with HBV reactivation risk could not be observed in this study. Recently, tocilizumab with steroids has been applied in severe COVID-19 patients to reduce the cytokine storm [10, 40], and the risk of HBV reactivation needs to be considered. Our reports indeed strengthen the evidence of the high HBV reactivation risk of TCZ in this population. Combining those reports, the overall $\mathrm{HBV}$ reactivation rate was 55\% (6/11) in HBsAg+ patients receiving TCZ (Supplement Table 1) [17-20, 22-31].

The early reactivation of HBV observed in our $\mathrm{HBsAg}+$ patients during TCZ therapy is consistent with other reports (Supplemental Table 2) [19, 21]. A case study from the Netherlands reported that one HBsAg+ patient experienced HBV reactivation with fulminant hepatitis 2 weeks after a single dose of TCZ [21]. Although antiviral treatment was immediately administered, hepatic failure ensued, requiring liver transplantation [21]. A prospective study from China reported that $\mathrm{HBV}$ reactivation occurred 1-3 months after patients received 3 doses of TCZ, with none experiencing hepatitis flare-up. After antiviral treatment, all these patients recovered well. In our study, the median time to reactivation from the first TCZ dose was 6 months. All HBsAg+ patients with HBV reactivation developed hepatitis flare-up, and 2 even had hyperbilirubinemia. After entecavir treatment, we observed improvements in liver function and hyperbilirubinemia. These reports indicate a short interval between the first dose of TCZ and HBV reactivation (Supplemental Table 2) in HBsAg+ patients. The reactivation may result in fulminant hepatitis despite early preemptive treatment.

In contrast to the high rate of HBV reactivation in HBsAg+ patients without antiviral prophylaxis, none of the HBsAg+ patients who received antiviral prophylaxis experienced HBV reactivation in our study (Fig. 1). Only two studies have reported the effect of antiviral prophylaxis in HBsAg+ patients receiving TCZ [19, 20]. Those studies included 12 patients in total, and none of the patients developed HBV reactivation under antiviral prophylaxis. Our report increases the strength of the evidence of antiviral prophylaxis for HBsAg+ RA patients receiving TCZ
(Supplement Table 1) [17-20]. Due to the high risk of HBV reactivation, short interval between TCZ administration and reactivation, and possibility of fulminant hepatitis, antiviral prophylactic agents should be given to $\mathrm{HBsAg}+$ patients before TCZ therapy.

The reported rates of $\mathrm{HBV}$ reactivation among $\mathrm{HBsAg}-/ \mathrm{HBcAb}+$ patients under $\mathrm{TCZ}$ treatment are inconsistent (Supplemental Table 1). [17-20, 22-31] A total of 11 studies have addressed the risk of HBV reactivation in $\mathrm{HBsAg}-/ \mathrm{anti}-\mathrm{HBc}+$ patients in small groups of patients (range, 4-48 patients) [19, 22-31]. The HBV reactivation rate ranged from 0 to $25 \%$, and the overall HBV reactivation rate was $2.2 \%$ (5/232). Four Japanese studies reported a total of 5 cases of $\mathrm{HBV}$ reactivation among $\mathrm{HBsAg}-/ \mathrm{HBcAb}+\mathrm{RA}$ patients receiving TCZ (Supplemental Table 3) [18, 28-31]. The viral load fluctuated between undetectable and detectable in most cases, and the reactivation resolved spontaneously without antiviral treatment. Our cohort included $64 \mathrm{HBsAg}-/ \mathrm{HBcAb}+$ patients who received TCZ; among them, there was one patient with HBsAg seroreversion and serum HBV DNA elevation up to $2.5 \times 10^{7} \mathrm{IU} / \mathrm{mL}$ without hepatitis flare-up. This result indicates that $\mathrm{HBs} \mathrm{Ag}-/ \mathrm{HBcAb}+$ patients are still at risk of HBV reactivation.

It should be noted that up to $26 \%$ of patients in this cohort received rituximab before tocilizumab therapy. Three of 4 HBV reactivation patients had a history of rituximab treatment. Rituximab therapy is thought to have a high risk of HBV reactivation by the AGA institute [7, 37]. However, studies on the HBV reactivation rate in rheumatic patients receiving rituximab are rare [38]. A previous study from Taiwan revealed that the incidence of HBV reactivation under rituximab treatment was up to $40 \%$ and $100 \%$ in $\mathrm{HBsAg}+$ RA patients without or with steroid treatment [17]. Our previous report demonstrated that the incidence of $\mathrm{HBV}$ reactivation was up to $60 \%$ and $8 \%$ in $\mathrm{HBs} \mathrm{Ag}+$ or $\mathrm{HBsAg}-/$ anti-HBc+ RA patients treated with rituximab [5]. According to the policy of National Health Insurance in Taiwan, RA patients with a poor response to rituximab should wait 6 months after the last dose of rituximab before switching to another biological agent. Although the time interval between rituximab and tocilizumab treatments was at least 6 months in our study, a history of rituximab treatment may still have some impact on HBV reactivation and is worthy of concern.

Similarly, a history of treatment with other bDMARDs may play a role in HBV reactivation. In the current cohort, all $\mathrm{HBsAg}+$ patients and 70\% of $\mathrm{HBs} \mathrm{Ag}$-/anti-HBc+ patients had a history of bDMARD use. Schwaneck et al. noted that a history of treatment with three or more bDMARDs was present among more anti-HBc+ patients with than without reactivation $(P=0.017)$ [39]. Previous report from our group demonstrated that a history of TNF-alpha inhibitor use was associated with $\mathrm{HBV}$ reactivation in $\mathrm{HBsAg}-/ \mathrm{anti}-\mathrm{HBc}+$ 
patients receiving rituximab [5]. Because of the low number of reactivation cases and the high number of cases with a history of bDMARDs treatment, our study cannot clarify the association between previous biological use and HBV reactivation. However, the higher HBV reactivation rate in this study than in previous reports (Supplemental Table 1) may suggest the importance of previous bDMARDs exposure.

This study has several limitations. First, the retrospective, observational design may lead to missing data. Some data (such as the quantified $\mathrm{HBsAg}, \mathrm{HBeAg}$, anti-HBe, anti-HBs, and HBV DNA levels) were incomplete. Thus, using those markers to predict the HBV reaction is not possible in this study. However, our investigation indeed provides more evidence about HBV reactivation in RA patients receiving TCZcontaining treatment. Further prospective studies are necessary to address the predictive role of these HBV markers. Second, our study only enrolled Asian patients; whether our findings are applicable to other populations is uncertain.

\section{Conclusion}

Tocilizumab is indicated in RA and has the potential to reduce the cytokine storm in severe COVID-19 patients. However, tocilizumab treatment carries the risk of HBV reactivation. The risk in HBsAg + patients is high, and it could be eliminated by antiviral prophylaxis. Although $\mathrm{HBsAg}-/ \mathrm{HBcAb}+$ patients have a very low risk, monitoring HBV DNA and HBV markers remains necessary. A history of bDMARDs or steroid use and a dynamic HBV serologic status may influence the risk of HBV reactivation, and further study is necessary to conclude the association.

Acknowledgments Not applicable.

Funding This study was funded by the Dalin Tzuchi General Hospital through grant number DTCRD109-T-34.

\section{Compliance with Ethical Standards}

Conflict of interest The authors declare no financial or nonfinancial interests.

Ethics approval and consent to participate The study conformed to the ethical guidelines of the 1975 Declaration of Helsinki as reflected by a priori approval by the Ethics Committee of Dalin Tzu Chi General Hospital (approval number B10901013). The requirement for informed consent was waived because this study was retrospective in nature, and the data analyzed did not include patient identification.

\section{References}

1. Lok AS, Ward JW, Perrillo RP, et al. Reactivation of hepatitis B during immunosuppressive therapy: potentially fatal yet preventable. Ann Intern Med. 2012;156:743-745.
2. Vassilopoulos D, Calabrese LH. Management of rheumatic disease with comorbid HBV or HCV infection. Nat Rev Rheumatol. 2012;8:348.

3. Di Bisceglie AM, Lok AS, Martin P, et al. Recent US Food and Drug Administration warnings on hepatitis B reactivation with immune-suppressing and anticancer drugs: just the tip of the iceberg? Hepatology. 2015;61:703-711.

4. Jansen TL, Mulder C. Rheumatology meets hepatology in 2012: a clinician's guideline for TNF inhibitors in hepatitis $\mathrm{B} / \mathrm{C}$ virus carriers. Expert Opin Biol Ther. 2012;12:391-393.

5. Kuo $\mathrm{MH}$, Tseng $\mathrm{CW}$, Lee $\mathrm{CH}$, et al. Moderate risk of hepatitis B virus reactivation in $\mathrm{HBs} \mathrm{Ag}(-) / \mathrm{HBcAb}(+)$ carriers receiving rituximab for rheumatoid arthritis. Sci Rep. 2020;10:2456.

6. Chen Y-M, Yang S-S, Chen D-Y. Risk-stratified management strategies for HBV reactivation in RA patients receiving biological and targeted therapy: a narrative review. J Microbiol Immunol Infect. 2019;52:1-8.

7. Reddy KR, Beavers KL, Hammond SP, et al. American Gastroenterological Association Institute guideline on the prevention and treatment of hepatitis B virus reactivation during immunosuppressive drug therapy. Gastroenterology. 2015;148:215-219. quiz e16-7.

8. Lan JL, Chen YM, Hsieh TY, et al. Kinetics of viral loads and risk of hepatitis B virus reactivation in hepatitis B core antibody-positive rheumatoid arthritis patients undergoing anti-tumour necrosis factor alpha therapy. Ann Rheum Dis. 2011;70:1719-1725.

9. Zhao J, Cui W, Tian BP. Efficacy of tocilizumab treatment in severely ill COVID-19 patients. Crit Care. 2020;24:524.

10. Narain S, Stefanov DG, Chau AS, et al. Comparative Survival Analysis of Immunomodulatory Therapy for Coronavirus Disease 2019 Cytokine Storm. Chest. 2020;S0012-3692:34901-1.

11. Lan T, Chang L, Wu L, et al. IL-6 plays a crucial role in HBV infection. J Clin Transl Hepatol. 2015;3:271-276.

12. Xia C, Liu Y, Chen Z, et al. Involvement of interleukin 6 in hepatitis B viral infection. Cell Physiol Biochem. 2015;37:677-686.

13. Hosel M, Quasdorff M, Wiegmann K, et al. Not interferon, but interleukin-6 controls early gene expression in hepatitis B virus infection. Hepatology. 2009;50:1773-1782.

14. Kuo T-M, Hu C-P, Chen Y-L, et al. HBV replication is significantly reduced by IL-6. J Biomed Sci. 2009;16:41.

15. Terrault NA, Lok AS, McMahon BJ, et al. Update on prevention, diagnosis, and treatment of chronic hepatitis B: AASLD 2018 hepatitis B guidance. Hepatology. 2018;67:1560-1599.

16. Winthrop KL, Mariette X, Silva JT, et al. ESCMID Study Group for Infections in Compromised Hosts (ESGICH) Consensus Document on the safety of targeted and biological therapies: an infectious diseases perspective (Soluble immune effector molecules [II]: agents targeting interleukins, immunoglobulins and complement factors). Clin Microbiol Infect. 2018;24:S21-S40.

17. Chen MH, Chen MH, Liu CY, et al. Hepatitis B virus reactivation in rheumatoid arthritis patients undergoing biologics treatment. $J$ Infect Dis. 2017;215:566-573.

18. Matsuzaki T, Eguchi K, Nagao N, et al. Hepatitis B virus reactivation in patients with rheumatoid arthritis: a single-center study. Mod Rheumatol. 2018;28:808-813.

19. Chen LF, Mo YQ, Jing J, et al. Short-course tocilizumab increases risk of hepatitis B virus reactivation in patients with rheumatoid arthritis: a prospective clinical observation. Int J Rheum Dis. 2017;20:859-869.

20. Lin CT, Huang WN, Hsieh CW, et al. Safety and effectiveness of tocilizumab in treating patients with rheumatoid arthritisa three-year study in Taiwan. J Microbiol Immunol Infect. 2019;52:141-150.

21. Sonneveld MJ, Murad SD, van der Eijk A, et al. Fulminant liver failure due to hepatitis $\mathrm{B}$ reactivation during treatment with tocilizumab. ACG Case Rep J. 2019;6:e0243. 
22. Ahn SS, Jung SM, Song JJ, et al. Safety of tocilizumab in rheumatoid arthritis patients with resolved hepatitis B virus infection: data from real-world experience. Yonsei Med J. 2018;59:452-456.

23. Papalopoulos I, Fanouriakis A, Kougkas N, et al. Liver safety of non-tumour necrosis factor inhibitors in rheumatic patients with past hepatitis B virus infection: an observational, controlled, longterm study. Clin Exp Rheumatol. 2018;36:102-109.

24. Barone M, Notarnicola A, Lopalco G, et al. Safety of long-term biologic therapy in rheumatologic patients with a previously resolved hepatitis B viral infection. Hepatology. 2015;62:40-46.

25. Mori S. Past hepatitis B virus infection in rheumatoid arthritis patients receiving biological and/or nonbiological disease-modifying antirheumatic drugs. Mod Rheumatol. 2011;21:621-627.

26. Carlino G, Fornaro M, Santo L, et al. Occult HBV infection may negatively impact on drug survival in patients with rheumatoid arthritis on treatment with a first biologic drug. An appraisal from the Biologic Apulian Registry (BIOPURE). Reumatismo. 2019;71:24-30.

27. Serling-Boyd N, Mohareb AM, Kim AY, et al. The use of tocilizumab and tofacitinib in patients with resolved hepatitis B infection: a case series. Ann Rheum Dis 2020.

28. Nakamura J, Nagashima T, Nagatani K, et al. Reactivation of hepatitis B virus in rheumatoid arthritis patients treated with biological disease-modifying antirheumatic drugs. Int J Rheum Dis. 2016;19:470-475.

29. Urata Y, Uesato R, Tanaka D, et al. Prevalence of reactivation of hepatitis B virus replication in rheumatoid arthritis patients. Mod Rheumatol. 2011;21:16-23.

30. Watanabe T, Fukae J, Fukaya S, et al. Incidence and risk factors for reactivation from resolved hepatitis $\mathrm{B}$ virus in rheumatoid arthritis patients treated with biological disease-modifying antirheumatic drugs. Int J Rheum Dis. 2019;22:574-582.

31. Fukuda W, Hanyu T, Katayama M, et al. Incidence of hepatitis $\mathrm{B}$ virus reactivation in patients with resolved infection on immunosuppressive therapy for rheumatic disease: a multicentre, prospective, observational study in Japan. Ann Rheum Dis. 2017;76:1051-1056.

32. Arnett FC, Edworthy SM, Bloch DA, et al. The American Rheumatism Association 1987 revised criteria for the classification of rheumatoid arthritis. Arthritis Rheum. 1988;31:315-324.

33. Aletaha D, Neogi T, Silman AJ, et al. 2010 rheumatoid arthritis classification criteria: an American College of Rheumatology/
European League Against Rheumatism collaborative initiative. Arthritis Rheum. 2010;62:2569-2581.

34. Smolen JS, Landewe R, Bijlsma J, et al. EULAR recommendations for the management of rheumatoid arthritis with synthetic and biological disease-modifying antirheumatic drugs: 2016 update. Ann Rheum Dis. 2017;76:960-977.

35. Emery P, Keystone E, Tony HP, et al. IL-6 receptor inhibition with tocilizumab improves treatment outcomes in patients with rheumatoid arthritis refractory to anti-tumour necrosis factor biologicals: results from a 24-week multicentre randomised placebocontrolled trial. Ann Rheum Dis. 2008;67:1516-1523.

36. Burmester GR, Rubbert-Roth A, Cantagrel A, et al. A randomised, double-blind, parallel-group study of the safety and efficacy of subcutaneous tocilizumab versus intravenous tocilizumab in combination with traditional disease-modifying antirheumatic drugs in patients with moderate to severe rheumatoid arthritis (SUMMACTA study). Ann Rheum Dis. 2014;73:69-74.

37. Perrillo RP, Gish R, Falck-Ytter YT. American Gastroenterological Association Institute technical review on prevention and treatment of hepatitis B virus reactivation during immunosuppressive drug therapy. Gastroenterology. 2015;148:e3.

38. Koutsianas C, Thomas K, Vassilopoulos D. Reactivation of hepatitis $\mathrm{B}$ virus infection in rheumatic diseases: risk and management considerations. Ther Adv Musculoskelet Dis. 2020;12:1759720X20912646.

39. Schwaneck EC, Krone M, Kreissl-Kemmer S, et al. Management of anti-HBc-positive patients with rheumatic diseases treated with disease-modifying antirheumatic drugs-a single-center analysis of 2054 patients. Clin Rheumatol. 2018;37:2963-2970.

40. Zhang $\mathrm{C}, \mathrm{Wu} \mathrm{Z}$, Li JW, et al. Cytokine release syndrome in severe COVID-19: interleukin-6 receptor antagonist tocilizumab may be the key to reduce mortality. Int J Antimicrob Agents. 2020;55:105954.

Publisher's Note Springer Nature remains neutral with regard to jurisdictional claims in published maps and institutional affiliations. 